\title{
A COMPILATION OF COMPARISONS ON THE ANALYTIC HIERARCHY PROCESS AND OTHERS MULTIPLE CRITERIA DECISION MAKING METHODS: SOME CASES DEVELOPED IN BRAZIL
}

\author{
Valério A. P. Salomon \\ Universidade Estadual Paulista \\ Guaratinguetá/SP - Brazil \\ salomon@feg.unesp.br \\ José Arnaldo B. Montevechi \\ Escola Federal de Engenharia de Itajubá \\ Itajubá /MG - Brazil \\ arnaldo@iem.efei.br
}

Keywords: Multiple Criteria Decision Making, Brazil

Summary: This paper intends to describe some comparisons on the Analytic Hierarchy Process and others multiple criteria decision making (MCDM) methods. This work also contributes introducing some researcher on MDCM performed at Latin America, most specifically in Brazil.

\section{Introduction}

Supplier selection is one of the decisions regarding to the Purchasing Process Management, as the order quantity and order timing decisions (Slack et al., 1998). For these last two examples of decisions we have well-known philosophies of production which give us decision support: Economic Order Quantity (EOQ), Materials Requirement Plan (MRP) and Just in Time (JiT, also known as Lean Production). In the most of the cases in real life, for the supplier selection decision making we can identify some features like no uncertainty, no risk, one single objective and one single attribute (criterion). This way, we can think about this decision making as a mechanical process: after some quotations the supplier who provides the lower price wins the order. However, the purchaser may face some situations, like a supplier providing with a little bit high price than another, but with a delivery time impressively lower. Other attributes regarding the suppliers may manifest: quality level, flexibility (ability to change products), reliable information, and so one. This way the mechanical decision making becomes a complex decision making, with multiple attributes to be considered and even the occurring of risk or uncertainty.

The multiple attribute assumption in the supplier selection decision has been claiming a long time ago (Deming, 1986). A way to do this is not simple: several new procurement policies has been proposed (Desai, 1996 and Weed, 1993). But, they bring others questions: how to establish a weight of importance for an attribute? And, how to evaluate the supplier performance in a qualitative criterion? For those whose the AHP (the Analytic Hierarchy Process developed from Saaty, 1977), or others MCDM methods, are familiar, there is at least one good answer emerging from that familiarity. But, in case of more than one MCDM method may be used, which method must be the chosen one? This was a question that came to us when we were facing a case of decision support about the supplier selection decision making. Our choice was for the AHP (Salomon, 1998), but we performed some investigation (Salomon et al. 1999) in order to "justify" the choice against another MCDM method.

\section{The Multiple Criteria Decision Making}


A MCDM method, as its own name suggests, is for use in situations when more than one criterion must be considered (ex.: cost, quality, servicing, etc.). Basically, these methods work with the same fundamental tool: the decision matrix. Table 1 shows a decision matrix used in a situation involving three alternatives and five different criteria. In a decision matrix, the $a_{i j}$ is the performance of alternative $i$ according to criterion $j$. The manner that a MDCM method works with the $a_{i j}$ is what becomes it different from another. Methods like the members of ELECTRE family (Elimination and Choice Translating Reality) only provide the sorting of the alternatives (in this case, a dominance principles based ranking). Others methods also provide performance measurements for all alternatives according every criterion, and alternatives sorting based on these performances.

\begin{tabular}{|c|c|c|c|c|c|}
\cline { 2 - 6 } \multicolumn{1}{c|}{} & Criterion 1 & Criterion 2 & Criterion 3 & Criterion 4 & Criterion 5 \\
\hline Alternative 1 & $a_{11}$ & $a_{12}$ & $a_{13}$ & $a_{14}$ & $a_{15}$ \\
\hline Alternative 2 & $a_{21}$ & $a_{22}$ & $a_{23}$ & $a_{24}$ & $a_{25}$ \\
\hline Alternative 3 & $a_{31}$ & $a_{32}$ & $a_{33}$ & $a_{34}$ & $a_{35}$ \\
\hline
\end{tabular}

Table 1 - The Decision Matrix

In the next section, some comparisons will be presented. It will be assumed that the reader has previous knowledge about the AHP method: how to treat judgments in order to get to the decision matrix. However, some basic information for others methods will be presented.

\section{Comparisons on AHP and other MCDM Methods}

\subsection{AHP, ELECTRE and TOPSIS}

The MCDM method TOPSIS (Technique for Order Preference by Similarity to Ideal Solution) has been developed from Hwang e Yoon (1981). It is a method with appeals as simplicity (easy to apply) and hypotheses based approach of a problem (the best and the worst situations).

Professor Edvaldo Santana from the Federal University of Santa Catarina (UFSC - Universidade Federal de Santa Catarina) has conducted a comparative study (Santana, 1996) on the methods AHP, ELECTRE and TOPSIS approaching the Industrial Location theme: the choice for a new automobile plant in the Brazilian state of Santa Catarina. The alternatives were the cities of Joinville, Blumenau and Imbituba; the criteria were the conditions of infrastructure, transportation facilities, local labor capability, basis industries potential, installed capacity expansion potential. In order to apply the ELECTRE and TOPSIS methods, experts from Regional Development Banks were consulted and was obtained for every criterion weights as $0.20,0.25,0.20,0.25$ and 0.10 . Those experts has also provided the values showed on table 2 .

\begin{tabular}{|l|c|c|c|c|c|}
\cline { 2 - 6 } \multicolumn{1}{c|}{} & Infrastructure & Transportation & $\begin{array}{c}\text { Labor } \\
\text { capability }\end{array}$ & $\begin{array}{c}\text { Basis } \\
\text { industries }\end{array}$ & $\begin{array}{c}\text { Capacity } \\
\text { expansion }\end{array}$ \\
\hline Joinville & 2 & 3 & 5 & 3 & 3 \\
\hline Blumenau & 2 & 3 & 4 & 2 & 3 \\
\hline Imbituba & 1 & 5 & 2 & 1 & 5 \\
\hline
\end{tabular}

Table 2 - Decision Matrix for ELECTRE e o TOPSIS

According to a concordance principle we conclude, by ELECTRE method, that the alternative Joinville dominates the others. But, we cannot made any else consideration regarding within the others alternatives. Alternating concordance and dominance limits the results were not sensitively changed. This implies that the only definitive conclusion is that the option Joinville is the most attractive one.

For the TOPSIS method the location to be selected is the one with the lower distance to the ideal solution $(\mathrm{A}+)$ and, simultaneously, the bigger distance to undesirable solution $(\mathrm{A}-)$. With table 2 data we have:

$$
\begin{aligned}
& \mathrm{A}_{+}=[2,5,5,3,5] \\
& \mathrm{A}_{-}=[1,3,2,1,3]
\end{aligned}
$$


The distances $\Delta_{i}^{+}$and $\Delta_{i}^{-}$of the alternatives $\left(\mathrm{A}_{i}\right)$ to the ideal and undesirable solution are computed by equations 1 and 2 :

$$
\begin{aligned}
& \Delta_{i}^{+}=\Sigma\left|a_{i j}-a_{j}^{+}\right| \\
& \Delta_{i}^{-}=\Sigma\left|a_{i j}-a_{j}^{-}\right|
\end{aligned}
$$

The alternative that provides the higher prioritization coefficient must be selected. The prioritization coefficient is obtained by equation 3 :

$$
\varphi_{i}=\Delta_{i}^{-} /\left(\Delta_{i}^{-}+\Delta_{i}^{-}\right)
$$

With the actual problem data we have:

\begin{tabular}{|l|c|c|c|}
\cline { 2 - 4 } \multicolumn{1}{c|}{} & $\Delta^{+}$ & $\Delta^{-}$ & $\varphi$ \\
\hline Joinville & 0.70 & 1.40 & 0.67 \\
\hline Blumenau & 1.05 & 1.05 & 0.50 \\
\hline Imbituba & 1.40 & 0.70 & 0.33 \\
\hline
\end{tabular}

Table 3 - Prioritization of alternatives according to TOPSIS

From table 3 we verify that, according to TOPSIS, Joinville will be the more attractive location, because it assure the lower distance to ideal solution and, simultaneously, the bigger distance to undesirable solution. Blumenau will be the second choice given the set of criteria.

In the AHP utilization one single expert was heard. The criteria (infrastructure, transportation facilities, local labor capability, basis industries potential, installed capacity expansion potential) have obtained the following weights: $0.14,0.34,0.14,0.34$ and 0.04 . The consistency index from the judgments among the criteria was 0.0386 . This way the priorization of the alternatives was configured as shown in table 4 , i. e., again Joinville will be the more attractive location. However, this time, followed by Imbituba.

\begin{tabular}{|l|c|}
\cline { 2 - 2 } \multicolumn{1}{c|}{} & Priority global \\
\hline Joinville & 0.39 \\
\hline Blumenau & 0.27 \\
\hline Imbituba & 0.34 \\
\hline
\end{tabular}

Table 4 - Prioritization of alternatives according to AHP

The main result observed from this case was the convergence to Joinville as alternative to be selected by the three methods. Santana (1996) had considered that "by the fact of the AHP assure the consistecy analysis of the judgments, the Saaty's model means, a priori, more robust than the others two". The TOPSIS was considered the more simple of the studied methods. The possibility to treat quantitatively a set of qualitative variables was an important feature that have been noted in all of these methods, what constitute itself in an advantage in a comparison with other methods as the cash flow analysis based, which need of transformations to monetary values.

Recently, Zanakis et al. (1998) have performed comparisons on AHP, ELECTRE, TOPSIS and two more methods, using simulated data. The results obtained by the AHP and TOPSIS methods return to show some similarity. But, this time, the results from TOPSIS and ELECTRE have presented significant divergence.

\subsection{AHP and MACBETH}

From a first observation, it seems that MACBETH (Measuring Attractiveness by a Categorical Based Evaluation Technique, developed by Bana e Costa and Vansnick, 1994) shows strong similarities within the AHP: "as the AHP and other multiple criteria decision support methods it accomplishes in two important phases, structuring and evaluation" (Schmidt, 1995). However, there are high differences in the manner within the phases must be conducted, that is beyond the nomenclature. 
In the MACBETH, the decision criteria - named as point of view - are "operated" by indicators. In the phase of evaluation, they are also pairwise judgment as in the AHP with the use of a matrix. The main differences are in the scale to be used in the judgments and in the validation of these judgments. In the MACBETH the validation of judgments may also be obtained by the theoretical consistency checking and by the semantic consistency checking. The MACBETH provides a visual preliminary consistency checking: in the judgment matrixes the attractiveness difference must increase from left to right and from bottom to up, given a necessary judgment sorting.

Schmidt (1995) set her work focus to the Graduation Program of Industrial Engineering at the Universidade Federal de Santa Catarina, from the student's point of view. The decision to be made was "How to improve the competitiveness of this Graduation Program?". The application begins very well conducted, by noting that "it was used as an illustration, and not as a concluding evidence, even because it will be necessary a higher range involving not only the students, but also the program chairman, the professors, the campus administration, and the society". Furthermore, it was also noted that "the students provide a significant sample of the criteria to be considered in case of a realistic evaluation will be necessary". The decision as modeled by Schmidt (1995) using the AHP has got seven alternatives (wrongly named "sub-criteria": lessons quality, infrastructure, professors quality, thesis evaluation, benefits to study, number of incoming students and name of the program) and three criteria (research qualification, society contribution and competitive formation). The judgments and the priorities synthesis (by eigenvector estimation) have pointed out the alternative infrastructure as the most relevant. This result has persisted after a sensibility analysis (only when the criterion competitive formation has get a weight higher than $77 \%$ the thesis evaluation becomes the most important alternative).

In our opinion, the application of MACBETH was a little prejudiced by the fact that this MCDM method evaluates criteria in a different way of the alternatives. Besides this incurred in an operational defect, one different solution for the decision was obtained: the alternatives with higher global priority was consulting and services, training courses to the community and infrastructure. The two new alternatives let us to think that the set of student (judges) was different of the application from AHP. This point has got no mention. Is important to remind the previous consideration that the main contribution of this work was an "illustrative" application of the MACBETH: the first historical application in Brazil and one of the oldest in the world. And that is the great importance from the work performed by Schmidt (1995): its pioneer character. It gives a significant contribution in showing some topics that were not clean at that point. For an example, the structuring phase was source of several works: Montibeller Neto (1996), Ensslin et al. (1997a) and Ensslin et al. (1997b).

As it was not mentioned by Schmidt (1995) if the same set of students performed the judgments for the applications of AHP and the MACBETH, the divergence of the results cannot be generalized. Even more, this kind of abstraction will need of more comparative works, which unfortunately did not turn to happen. This fact becomes the presented work a kind of rarity. 


\subsection{AHP and ANP}

Few years ago, it was proposed by Saaty (1996) a new MCDM method, developed from AHP in order to solve one of AHP limitations: the necessary independence among elements from an hierarchical level (or node). In this proposal the AHP was defined as a particular case of the ANP (Analytic Network Process). Salomon and Montevechi (1998) have presented a comparison between these methods through a illustrative example proposed by Saaty (1996): the estimation of market share in the fast-food American market.

In the segment of hamburgers, they came to three alternatives: McDonald's, Burger King and Wendy's. Criteria that must to be included are the propaganda (promotions, frequency and creativity), quality (nutrition, taste and size of portion), price and location. The problem could be analyzed by the AHP throughout simple or complex hierarchies and by the ANP with a network. But, the existence of dependence was clear if we think that nutrition is what Wendy's sells and Burger King competes in size. So, these two aspects from quality influence propaganda and price. More over, when a competitor introduces something new, almost always it is followed (as close as possible) by the others. The data from Table 5 let us analyze how the assumption or not of dependence among criteria or alternatives affects the final results.

\begin{tabular}{|l|c|c|c|c|}
\cline { 2 - 5 } \multicolumn{1}{c|}{} & $\begin{array}{c}\text { Simple } \\
\text { hierarchy }\end{array}$ & $\begin{array}{c}\text { Complex } \\
\text { hierarchy }\end{array}$ & Network & Real values $^{1}$ \\
\hline McDonald's & 0.4640 & 0.5427 & 0.5603 & 0.5823 \\
\hline Burger King & 0.2305 & 0.2689 & 0.2778 & 0.2857 \\
\hline Wendy's & 0.3055 & 0.1884 & 0.1621 & 0.1320 \\
\hline
\end{tabular}

Table 5 - Comparisons of results from AHP and ANP

In this case, ANP gives higher precision results than AHP. Moreover, we can note that analyzing a problem when the dependence between criteria and alternatives is present, there is a risk to get results which provide unrealistic rankings. However to get to the prioritization with a complex hierarchy there will be necessary 79 judgments; for a more simple hierarchy could be necessary only 12 judgments! A network with the same numbers of elements of a complex hierarchy, but loaded of dependencies could need 624 judgments (602 only for the "supermatrix" shown in Saaty, 1996).

Measuring the decision effort with the number of judgment, implies that the decrease of this effort emerges as a source for new researches. Two ways of decrease this effort was presented by Salomon and Montevechi (1998) - the departmentalization of judgments (as noted by Saaty, 1996) and the use of incomplete pairwise comparisons (as proposed by Harker, 1987). Unfortunately, if there are some works in this area, they do not have considerable repercussion. This work's authors are researching on AHP applications, but they not realize any new ANP research. It means that they still have no conditions to affirmatively answer their question: "ANP will be the successor of AHP?"

\section{Conclusions}

Even so the origin of the Multiple Criteria Decision Making (MCDM) is attributed to works that date of the mid of this century (Churchman et al., 1957), this subject continues to fascinate researchers of all the world, as it could be observed through this article.

\footnotetext{
${ }^{1}$ Normalized from Market Share Reporter (1994 apud Saaty, 1996)
} 
The object of study of the present work was only one MDMC method (the AHP). Besides this, it was given to the reader the chance to know other methods. None of the works presented in the previous section has concluded that the AHP as an inferior MCDM method. By the opposite, the results gotten for the different methods, in the most of cases, may be considered similar. Several advantages of the application of the AHP has been observed in all the cases.

From the experience of the studied cases, is presented as the final conclusion that, if will be determined to use a MCDM method as a decision support, to answer the eminent decision of which method to use, the situation within the decision must be taken is what will lead to the choice. Still thus, if there will be time to take the decision, if there will be no more than nine alternatives, and if these alternatives and the criteria of decision was total independent, we suggest the use of the AHP, expecting the attainment of good results: an excellent, or maybe, the optimum solution!

\section{References}

Bana e Costa, C. and J. C. Vansnick (1994), "MACBETH: an interactive path towards the construction of cardinal value functions", International Transactions in Operational Research, vol. 1, n. 4, p. 489-500

Churchman, C. W., R. L. Ackoff and E. L. Arnoff (1957), Introduction to Operations Research, John Wiley \& Sons, New York (USA)

Deming, W. E. (1986), Out of Crisis, Massachusetts Institute of Technology, Cambridge (USA)

Desai, M. P. (1996), "Implementing a supplier scoreboard program", Quality Progress, vol. 29, n. 2, p. $73-75$

Ensslin, L., G. Montibeller Neto and S. M. Noronha (1997a), "Constructing a plan for development using cognitive maps", IIIrd International Congress of Industrial Engineering (Proceedings CD-ROM), Universidade Federal do Rio Grande do Sul, Gramado (Brazil)

Ensslin, L., I. J. Zanella and E. Ensslin (1997b), "Structuring a real-world MCDA application", IIIrd International Congress of Industrial Engineering (Proceedings CD-ROM), Universidade Federal do Rio Grande do Sul, Gramado (Brazil)

Harker, P. T., "Incomplete pairwise comparisons in the analytic hierarchy process", Mathematical Modeling, v. 9, n. 11, p. 837-848, 1987

Hwang, C. L. and K. Yoon (1981), Multiple Attribute Decision Making: Methods and Applications, Springer-Verlag, Berlin (Germany)

Montibeller Neto, G. (1996), Mapas Cognitivos: uma ferramenta de apoio à estruturação de problemas, MSc dissertation, Universidade Federal de Santa Catarina, Florianópolis (Brazil)

Saaty, T. L. (1977), "A scaling method for priorities in hierarchical structures”, Journal of Mathematical Psychology, vol. 15, p. 234-281

Saaty, T. L. (1996), Decision Making with Dependence and Feedback: the Analytic Network Process, RWS Publications, Pittsburgh (USA)

Salomon, V. A. P. and J. A. B. Montevechi (1998), "Método de análise em redes: o sucessor do método de análise hierárquica ?", Produto \& Produção, vol. 2, no. 3, p. 107-117

Salomon, V. A. P. (1998), Contribuição para Auxílio à Decisão em Processos de Compras, MSc dissertation, Escola Federal de Engenharia de Itajubá, Itajubá (Brazil) 
Salomon, V. A. P., J. A. B. Montevechi and E. O. Pamplona (1999), "Justificativas para aplicação do método de análise hierárquica", Vth International Congress of Industrial Engineering (Proceedings $C D$-ROM), Universidade Federal do Rio de Janeiro, Rio de Janeiro (Brazil)

Santana, E. A. (1996), "Múltiplos critérios: uma alternativa, apesar das fragilidades das soluções", Ind International Congress of Industrial Engineering (Proceedings CD-ROM), Universidade Metodista de Piracicaba, Piracicaba (Brazil)

Schmidt, A. M. (1995), Processo de Apoio à Tomada de Decisão Abordagens: AHP e MACBETH, MSc dissertation, Universidade Federal de Santa Catarina, Florianópolis (Brazil)

Slack, N., S. Chambers, C. Harland, A. Harrison and R. Johnston (1998), Operations Management, Pitman Publishing, London (United Kingdom)

Weed, R. M. (1993), "The proof is in the pavement", Civil Engineering, August, p. 67-69

Zanakis, S. H., A. Solomon, N. Wishart and S. Dublish (1998), "Multi-attribute decision making: a simulation comparison of select methods", European Journal of Operational Research, n. 107, p. 507529 
